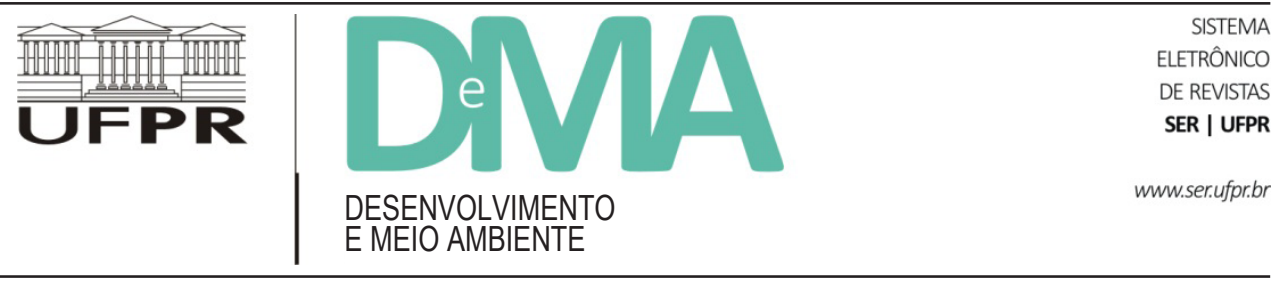

\title{
Território e comunidades étnicas/locais: entre pressões de grandes empreendimentos e o acesso a políticas públicas ${ }^{1}$
}

\section{Territory and Ethnic/Local Communities: Pressure for Large Enterprises and Access to Public Policies}

\author{
Maristela Oliveira de ANDRADE ${ }^{*}$, Adjane de Araújo MACHADO², Ivys Medeiros da COSTA², Rafaella Soares \\ ESPÍNOLA ${ }^{4}$ \\ ${ }^{1}$ Universidade Federal da Paraíba (UFPB), João Pessoa, PB, Brasil. \\ ${ }^{2}$ Escola Estadual de Ensino Médio e Ensino Médio Integrado Presidente João Goulart, João Pessoa, PB, Brasil. \\ ${ }^{3}$ Programa Regional de Pós-Graduação em Meio Ambiente e Desenvolvimento, Universidade Federal da Paraíba (UFPB), João Pessoa, PB, Brasil. \\ ${ }^{4}$ Secretaria de Turismo da Prefeitura Municipal de Conde, PB, Brasil. \\ *E-mail de contato: andrademaristela@hotmail.com
}

Artigo recebido em 7 de julho de 2014, versão final aceita em 3 de novembro de 2014.

RESUMO: Este trabalho propõe uma reflexão a partir de uma pesquisa sobre múltiplas experiências em territórios indígenas, quilombolas e de populações locais com fronteiras ou sobreposições com unidades de conservação na Paraíba, confrontados com grandes empreendimentos econômicos ou alvo de políticas públicas direcionadas a eles. Com base em uma análise comparativa dessas experiências foram identificados, de um lado, conflitos socioambientais por disputas territoriais diante da implantação de grandes empreendimentos capitalistas privados; e, por outro lado, uma aproximação entre os interesses em favor do desenvolvimento local sustentável e da conservação ambiental, através de políticas sociais e ambientais como fruto da mediação do Estado. Como resultado desta pesquisa, foram vislumbrados sinais, ainda que frágeis, da formação de um fórum comum em que pesquisadores das ciências humanas e naturais dialogam para construir uma relação mais simétrica entre sociedade e natureza.

Palavras-chave: território; conflitos socioambientais; sustentabilidade.

ABSTRACT: This paper proposes a reflection based on a research about of multiple experiences in indigenous territories, quilombolas and local population with borders or overlays with conservation units in Paraíba, confronted with major economic ventures or the target of public policies directed to them. Based on a comparative analysis of, these experiences, environmental conflicts due to territorial disputes after the deployment of large private enterprises were identified, on one hand, and, on the other hand, a rapprochement between the interests in favor

1 Trabalho apresentado na IV Reunião Equatorial de Antropologia e XIII ABANNE, Fortaleza, 04 a 07 agosto 2013 na Mesa: A (des?)Articulação de gênero, Ambiente e Etnicidade diante de projetos de desenvolvimento. 
of local sustainable development and environmental conservation, through social and environmental policies as a result of the mediation of the State. Results of this research showed fragile signals of creation of a common venue where human and natural science researchers may dialogue to build a relationship between society and nature.

Keywords: territories; environmental conflicts; sustainability.

\section{Introdução}

A concessão de direitos territoriais pelo estado brasileiro a grupos étnicos, indígenas e quilombolas, como também às chamadas populações tradicionais agricultores familiares e pescadores artesanais -, tem levado a antropologia a uma aproximação com o tema do desenvolvimento, uma vez que esses direitos garantem o acesso dessas populações a políticas de inclusão social. Paralelamente, o Estado vem adotando uma política de demarcação de terras voltada para a criação de unidades de conservação, como forma de impedir a devastação de áreas de florestas e outros atributos naturais que se mantiveram bem preservados.

Entretanto, essas demarcações de terra para finalidades estranhas à lógica do capitalismo globalizado se confrontam com exigências de instalações de grandes infraestruturas para dar suporte ao crescimento econômico, produzindo reações e conflitos socioambientais de grande repercussão na mídia na atualidade. Por exemplo, seguindo a racionalidade do capitalismo globalizado, ao investir na produção de energia hidrelétrica o Estado dá à terra um valor monetário de mercado, entrando em confronto com populações ribeirinhas, que, possuindo outra racionalidade, "resguardam a terra como patrimônio da família e da comunidade, defendido pela memória coletiva e por regras de uso e compartilhamento dos recursos", conforme Zhouri \& Oliveira (2007, p. 120).

O setor ruralista, visando alterar a legislação indigenista brasileira, tem feito uma campanha insistente propondo retirar a competência da Fundação Nacional do Índio, FUNAI, de demarcação das terras indígenas para passar para o Congresso Nacional, movimento denunciado pelo antropólogo João Pacheco de Oliveira (apud Tosta, 2013) ao jornal Estadão. Ele argumenta que a demarcação de territórios indígenas, por serem igualmente reservas ambientais e santuários ecológicos, é do interesse do governo. “As áreas indígenas não são apenas destinadas aos indígenas, em grande parte são reservas ambientais [...] E não são terras dos indígenas, são terras da União" (Oliveira apud Tosta, 2013, p. 2).

A convergência entre os interesses de conservação da natureza e os de promoção da diversidade cultural - tal como na criação das reservas extrativistas - representa a possibilidade de reunir o coletivo, formado segundo Latour (2004 p. 407): “de humanos e de não-humanos, capazes de assentarem como cidadãos, com a condição de proceder a divisões de capacidades". Da divisão entre a política, que supõe valores, e a ciência, a "veracidade" dos fatos, emerge a dúvida nos porta-vozes. Cabe ressaltar que as controvérsias ocorrem tanto na ciência, diante de teorias conflitantes como as do aquecimento global, quanto na política, através de instrumentos como o Mecanismo de Desenvolvimento Limpo - MDL, com seus defensores e detratores.

Nesse contexto, os antropólogos têm sido chamados a participar de equipes multi e interdisciplinares para tratar da dimensão humana do ambiente, ao lado de biólogos e de outros pesquisadores ligados às ciências naturais, para a formulação ou para a avaliação de políticas que envolvem a proteção da natureza e os direitos territoriais de povos tradicionais. Apesar disso, as controvérsias ainda se manifestam com a persistência de argumentos de biólogos/ecólogos de que a conservação da biodiversidade depende da exclusão dos humanos e de suas práticas de certas áreas do planeta. Enquanto antropólogos, baseados em estudos da antropologia ecológica, contestam com argumentos tais como os de Balée (apud Castro 2002, p. 326): “a 'natureza' amazônica é parte e resultado de uma longa história cultural [...] aliás, as florestas antropogênicas apresentam maior biodiversidade que as florestas não-perturbadas."

O presente artigo visa se inserir nessa discussão através do trabalho de uma equipe integrante do Grupo Interdisciplinar de Pesquisa em Cultura/Sociedade e 
Ambiente - GIPCSA ${ }^{2}$, que desenvolve uma pesquisa que agrega um conjunto de subprojetos, intitulada "A gestão ambiental compartilhada - setor público, privado, terceiro setor e associações comunitárias - em ações voltadas para a sustentabilidade socioambiental na Paraíba". Os subprojetos investigaram a interface entre populações locais, grupos étnicos e entre conflitos socioambientais frente a diferentes lógicas de fomento ao desenvolvimento como os grandes empreendimentos capitalistas, ou os programas de desenvolvimento local através das políticas públicas. As experiências de gestão compartilhada investigadas se situaram entre 2008 e 2013 e resultaram do acesso a políticas públicas, por grupos étnicos ou populações tradicionais/locais.

As populações locais, designadas também como populações tradicionais, se definem no marco deste trabalho a partir de critérios formulados por Cunha \& Almeida (2001, p. 192): “a categoria de 'populações tradicionais' é ocupada por sujeitos políticos que estão dispostos a conferir-lhe substância, isto é, que estão dispostos a uma série de práticas, em troca de algum tipo de benefício e, sobretudo, de direitos territoriais".

A metodologia de análise baseou-se no levantamento dos dados reunidos pelos subprojetos, complementado por um questionário, aplicado aos mestrandos responsáveis pelos subprojetos, para obter dados adicionais. A análise dos resultados foi feita sob a perspectiva da comparação das diferentes experiências e da discussão possibilitada pela dinâmica dos debates sobre os resultados dos subprojetos e sobre o marco teórico conceitual que será apresentado a seguir.

\section{As disputas territoriais, a etnicidade e o etnodesenvolvimento}

Para entender como a antropologia participa do debate sobre a relação entre sociedade e meio ambiente serão abordadas duas vertentes: a antropologia ecológica e a ecologia política, que representam duas tendências de orientações distintas. A primeira privilegia a dimensão material dessa relação e a segunda a dimensão política, que envolve uma disputa entre a conservação da natureza e os interesses de exploração dos recursos naturais por parte da sociedade.

Dois representantes contemporâneos da primeira tendência, Foladari \& Taks (2004), identificam duas linhas de investigação: a que procura desmistificar preconceitos sobre uma relação harmoniosa entre sociedades pré-industriais e a natureza; e a outra voltada para abordar os problemas ambientais e o rumo das sociedades para tornarem-se mais sustentáveis. Embora a antropologia venha contribuindo para a desconstrução do mito da "sabedoria ambiental primitiva", os governos baseados nesta premissa vêm adotando políticas para o desenvolvimento destinado a agricultores familiares e indígenas, entre outras populações, em seus respectivos territórios.

Para pensar sobre a situação dos territórios étnicos dos índios do Nordeste, Oliveira (1998) formulou a noção de territorialização, que é pertinente para considerar igualmente a situação dos territórios dos quilombolas (Arruti, 2006), os quais também são objeto de análise neste trabalho. Conforme Oliveira (1998), esta noção supõe o desencadeamento de:

[...] um processo de reorganização social que implica: 1) a criação de uma nova unidade sociocultural mediante o estabelecimento de uma identidade étnica diferenciadora; 2) a constituição de mecanismos políticos especializados; 3 ) a redefinição do controle social sobre os recursos ambientais; 4) a reelaboração da cultura e da relação com o passado (p. 55).

Processos de territorialização foram detectados na Paraíba, tanto na terra indígena - TI, quanto em terra de quilombolas, assim como o fenômeno de sobreposição de TI com Área de Proteção Ambiental - APA, de modo que ele suscita várias situações de conflito e reconfigurações do território. A gestão territorial definida pelo Estado apresenta, assim, duas lógicas: a do Instituto Brasileiro do Meio Ambiente e dos Recursos Naturais Renováveis -

\footnotetext{
2 O grupo é composto por bacharéis em direito, turismólogas, jornalistas, biólogos e pedagogas sob a coordenação de uma antropóloga, primeira autora que integra desde 1996 uma equipe interdisciplinar no Programa de Pós-Graduação em Desenvolvimento e Meio Ambiente da Universidade Federal da Paraíba.
} 
IBAMA para as unidades de conservação e a da FUNAI para as terras indígenas (Mendes, 2008), havendo com frequência uma disputa entre as duas lógicas, considerando a existência no Brasil de inúmeras situações em que ocorrem sobreposições entre TI com UC.

Com relação aos territórios quilombolas, a contribuição de Arruti (2006) converge para a noção de fronteiras étnicas de Barth (2011), que atribui um sentido relacional e político ao conceito de etnicidade. Entretanto, deve ser salientado que a luta por territórios requer uma política identitária de autorreconhecimento, que pode dar à etnicidade uma conotação instrumental. Contudo, Barth (2011) rejeita esta posição reducionista, considerando a existência de outras situações concretas em que a reivindicação de grupos étnicos não é material ou utilitária.

Por outro lado, a etnicidade se relaciona negativamente com o desenvolvimento capitalista, gerando uma crítica aos efeitos destrutivos das políticas desenvolvimentistas, responsabilizada por provocar etnocídios. Esta crítica inspirou a formulação do conceito de etnodesenvolvimento por Stavenhagen e Batalla ainda na década de 1970, como um modelo que parte das experiências históricas dos indígenas em que os projetos são inspirados nos valores e aspirações deles (Batalla apud Medeiros, 2011).

Para Little (2002), o etnodesenvolvimento deve se basear no princípio da autonomia e no reconhecimento dos direitos à diversidade cultural. Inspirado em Sahlins (1997), o autor destaca o fenômeno de 'indigenização da modernização', em que a 'tradição' é submetida a um processo de constante transformação, significando assimilações diferenciadas da modernização por diferentes grupos étnicos. Inclusive, as novas teorias da etnicidade rejeitam uma atribuição essencialista ou substancialista à cultura, em que os grupos étnicos sejam vistos como suporte da cultura:

A dessubstancialização dos grupos étnicos operada pelos antropólogos sociais continua sendo a principal descoberta e a aquisição fundamental em que se apoiam todas as pesquisas atuais sobre etnicidade (Poutignat \& Streiff-Fenart 2011, p. 129).
Little (2002) aponta os desafios da formulação de programas de desenvolvimento a partir do reconhecimento de direitos oriundos da diversidade cultural através da noção de estados pluriétnicos, devido à tendência universalizante do conceito de desenvolvimento. Neste sentido, este autor atribui um papel estratégico à antropologia no desafio de compatibilizar o desenvolvimento com o princípio da diversidade cultural. Isso ocorre, uma vez que o reconhecimento de direitos territoriais de grupos étnicos deve ser acompanhado do acesso a políticas sociais de desenvolvimento, de modo a evitar a marginalização deles.

\section{Território étnico e APA na Paraíba em confronto com grandes empreendimentos}

O campo empírico das pesquisas ${ }^{3}$ em foco está representado pelas experiências situadas na interface entre etnicidade, ambiente e desenvolvimento no âmbito da Paraíba, tendo sido privilegiados os espaços litorâneos - o litoral norte e o litoral sul - embora outras experiências situadas fora deles tenham sido incorporadas ao quadro analítico.

O litoral norte da Paraíba se caracteriza pela presença marcante do povo indígena Potiguara, não havendo registro de comunidades quilombolas nessa região do estado. A Terra Indígena Potiguara vem sendo alvo de diferentes pressões oriundas de grandes empreendimentos econômicos desde o final da década de 1910, quando um grupo sueco instalou a Companhia de Tecidos Rio Tinto e construiu ao lado da fábrica uma vila operária, invadindo uma parte considerável do território indígena (Costa, 2012).

A Terra Indígena Potiguara demarcada e reconhecida em 1983, homologada através do Decreto Presidencial no 267 de 29/10/1991, com 21.238 hectares, ainda mantém uma porção de terra em litígio denominada Terra Indígena Potiguara de Monte Mor, que se encontra em disputa, envolvendo grandes empreendimentos sucroalcooleiros. As pressões deste pujante setor econômico constituem um obstáculo poderoso à homologação desta

\footnotetext{
As pesquisas em foco resultaram das dissertações de mestrado do Programa de Pós-graduação em Desenvolvimento e Meio Ambiente Prodema/UFPB.
} 
parcela do território que foi demarcada pela Portaria $\mathrm{n}^{\circ} 2.135$, de 14 de dezembro de 2007 do Ministério da Justiça (Costa, 2012).

Com a criação de uma área de proteção ambiental federal, em 1993, a APA da Barra do rio Mamanguape com sobreposição com a TI Potiguara e a TI Potiguara de Monte Mor, novos conflitos foram ensejados entre os indígenas e o órgão ambiental. Conflitos em decorrência da irregularidade da carcinicultura praticada por famílias indígenas desde meados da década de 1990, dentro da TI na área de sobreposição com a APA. Nesse cenário se acham ainda os atores governamentais: Ibama, Funai, Superintendência de Administração do Meio Ambiente - Sudema, Ministério Público - MP e suas divergências quanto ao alcance e limite de suas competências (Moreira \& Andrade, 2009). A Tabela 1 expressa o confronto acima referido.

A partir de meados dos anos 1970 o governo brasileiro, através do Programa Nacional do Álcool Proálcool, introduziu o plantio da monocultura de cana-de-açúcar na região, incluindo a TI na fase da Revolução Verde. Nos anos 1990, foi introduzida a carcinicultura com empreendimentos de cultivo intensivo no entorno da TI e dentro dela, quando foram implantados viveiros pelos próprios indígenas na fase da Revolução Azul (Moreira \& Andrade, 2008). Atualmente, a TI se encontra cercada por grandes empreendimentos sucroalcooleiros.

A partir dessas informações, cabe perceber diferenças entre as situações de aldeias afetadas pelas zonas canavieiras e de carcinicultura, advertindo que essas atividades não se encontram apenas na circunvizinhan- ça da terra, mas dentro dela, e afetam diferentemente o ecossistema do estuário onde elas estão situadas, assim como a vida dos Potiguaras. Quanto ao litígio relativo ao conflito fundiário na terra de Monte Mor, entrou em cena o grupo detentor do espólio da Companhia de Tecidos Rio Tinto, que se mantém como um ator social ativo nesta arena do conflito. Contudo, a legislação indígena assegura a autonomia dos índios em seus territórios, sendo mediada pela Funai em confronto com o Instituto Chico Mendes de Conservação da Biodiversidade - ICMBio, que se apoia em uma legislação a qual, em tese, limitaria os direitos indígenas (Costa, 2014).

A carcinicultura familiar na TI Potiguara é explorada por 23 famílias, nas quatro aldeias do município de Marcação, com a presença de viveiros de camarão Camurupim, Caieira, Brejinho e Tramataia -, tendo sido introduzida no início da década de 1990, de acordo com pesquisa realizada por Moreira \& Andrade (2008). Na aldeia de Tramataia, 14 famílias conseguiram apoio da agência COOPERAR-Paraíba com recursos financeiros do Banco Mundial, através do Plano de Participação das Populações Indígenas - PPPI dentro do Projeto de Redução da Pobreza Rural - PRPR no período de 1998 a 2006 (Cooperar Paraíba, 2007).

Em 2007, foi criada, por incentivo da agência COOPERAR-Paraíba, a Cooperativa dos Carcinicultores de Tramataia Altino Figueiredo da Silva, já na fase de declínio da atividade (Moreira \& Andrade, 2008). Com isso, a produção de camarão foi abandonada praticamente pelos grandes produtores, passando a ser praticada por produtores de menor porte, inclusive produção fa-

TABELA 1 - Território Indígena dos Potiguaras e a APA do rio Mamanguape/PB, no litoral norte, em confronto com grandes projetos de desenvolvimento.

\begin{tabular}{|c|c|c|c|c|}
\hline Objeto da pesquisa & Área de estudo & $\begin{array}{c}\text { Projeto de } \\
\text { desenvolvimento }\end{array}$ & Impactos ambientais & $\begin{array}{c}\text { Atores envolvidos nos } \\
\text { conflitos }\end{array}$ \\
\hline $\begin{array}{l}\text { Conflitos fundiários } \\
\text { Terra Indígena (Monte } \\
\text { Mor) e usinas de ativi- } \\
\text { dade canavieira }\end{array}$ & $\begin{array}{l}\text { Terra Indígena em } \\
\text { litígio e sobreposição } \\
\text { com APA }\end{array}$ & $\begin{array}{l}\text { Revolução Verde: In- } \\
\text { trodução do plantio } \\
\text { de cana-de-açúcar - } \\
\text { Proálcool }\end{array}$ & $\begin{array}{l}\text { Poluição no rio e no } \\
\text { solo proveniente uso } \\
\text { agrotóxicos; assorea- } \\
\text { mento do rio; erosão } \\
\text { do solo. }\end{array}$ & $\begin{array}{l}\text { Índios Potiguara; Usinas } \\
\text { sucroalcooleiras Compa- } \\
\text { nhia Têxtil Rio Tinto e } \\
\text { seus herdeiros; Funai; MP; } \\
\text { ICMbio e IBAMA. }\end{array}$ \\
\hline $\begin{array}{l}\text { Conflitos socioambien- } \\
\text { tais da carcinicultura } \\
\text { indígena e não indígena }\end{array}$ & $\begin{array}{l}\text { Terra Indígena Poti- } \\
\text { guara e sobreposição } \\
\text { com APA de Maman- } \\
\text { guape }\end{array}$ & $\begin{array}{l}\text { Revolução Azul: } \\
\text { Introdução } \\
\text { carcinicultura }\end{array}$ & $\begin{array}{l}\text { Desmatamento do } \\
\text { manguezal; despejo de } \\
\text { efluentes da carcinicul- } \\
\text { tura }\end{array}$ & $\begin{array}{l}\text { Índios carcinicultores; } \\
\text { grandes empresários carci- } \\
\text { nicultura; } \\
\text { Funai; Ibama; Sudema; MP }\end{array}$ \\
\hline
\end{tabular}

FONTE: Moreira \& Andrade (2009); Costa (2014). 
miliar para atender ao mercado interno. Outra atividade aquícola registrada também em Tramataia foi o cultivo de ostras, que tem características mais sustentáveis de produção, conforme outra pesquisa na área (Cavalcanti, 2013) e a atividade extrativista de mariscagem, com aproximadamente 20 famílias (Cardoso \& Guimarães, 2012; Silva, 2013).

No litoral sul há uma presença marcante de comunidades quilombolas, assim como assentamentos rurais e outras populações locais, como pescadores. O conjunto dessas comunidades vem se confrontando com a instalação de empreendimentos turísticos, com a expansão urbana e com o crescimento dos empreendimentos imobiliários, desde que a região tornou-se um dos principais destinos turísticos no estado.

As comunidades quilombolas do litoral sul, situadas no município de Conde/PB, Gurugi I, Gurugi II, Ipiranga e Mituaçu, lutaram pela posse da terra contra proprietários rurais, sendo divididas em assentamento de Reforma Agrária. Em 2006, essas comunidades foram reconhecidas pela Fundação Cultural Palmares como território quilombola único, passando a ter acesso a outros direitos assegurados aos quilombolas (Monteiro \& Garcia, 2010). Cabe registrar, ainda, a comunidade quilombola de Paratibe, situada no município de João Pessoa, na fronteira com o município do Conde, que também foi incluída nas comunidades afetadas pela expansão imobiliária e pela transformação das praias do litoral sul em destino turístico.

No litoral sul, destaca-se também a presença da APA de Tambaba, criada por Decreto Estadual em 2002, a qual possui comunidades rurais em seu interior, que encontram-se ameaçadas de perderem parte do seu território para a instalação de um complexo turístico que prevê a construção de 03 resorts, condomínios residenciais tipo flats, espaço de lazer e entretenimento, além de campo de golfe (Espínola \& Andrade, 2012). A audiência pública realizada em 14 de janeiro de 2013, para apresentação, à comunidade, do relatório de impacto ambiental - RIMA do empreendimento no município, assim como o projeto, contou com a presença de grande público, através do qual se manifestou a resistência da comunidade ao empreendimento, apesar da existência de forças políticas favoráveis a liberar parte da APA como de interesse público.

Para expressar os confrontos detectados nas pesquisas envolvendo diferentes grupos e comunidades tradicionais/locais do litoral sul com grandes projetos de desenvolvimento, ver a Tabela 2.

Os grandes projetos de desenvolvimento focados no litoral sul se associam à vocação turística adquirida nas ultimas décadas e à expansão imobiliária, que ameaçam as diferentes comunidades locais (Espínola \& Andrade, 2012). O segmento dos "farofeiros" e a população local, incluindo os pescadores, foram identificados como os primeiros atores atingidos pela recente inserção de resorts na área (Machado, 2012).

Na pesquisa sobre a introdução de resorts no litoral sul paraibano, foram feitas entrevistas com as lideranças das comunidades locais, sendo detectado o reconhecimento dos impactos ambientais dos empreendimentos, assim como uma expectativa de participar deste mercado turístico, comercializando artesanato, produtos agrícolas e pesqueiros, e espetáculos culturais. Contatos realizados com os gerentes de empreendimentos turísticos locais para a mostra desses produtos não tiveram qualquer êxito. Porém a inserção obtida até o momento tem sido com uma empregabilidade ainda precária de membros dessas comunidades, que passaram a complementar suas rendas através de trabalho nos empreendimentos turísticos, na condição de vigias noturnos e de camareiras (Espínola \& Andrade, 2012).

A inauguração do primeiro resort no litoral sul coincidiu com a entrada em vigor da Lei municipal $575 / 2009$ que regulamenta a cobrança de taxas de turismo para acesso de ônibus de excursões às praias do município do Conde/PB (Machado, 2012). A referida lei acabou por excluir os "farofeiros", tradicionais frequentadores das praias do município, bem como afetou a população local que comercializava uma variedade de produtos e serviços em bares e em barracas instaladas nas praias - sendo os "farofeiros" um importante segmento da clientela desses estabelecimentos (Machado, 2012). Nesse contexto, se por um lado a população local

\footnotetext{
${ }^{4}$ O termo farofeiro, no sentido aqui empregado, de acordo com o Dicionário Houaiss da Língua Portuguesa (2001 p. 1309), significa “aquele que frequenta a praia levando farnel de alimentos que geralmente contém frango assado e farofa”.
} 
TABELA 2 - Comunidades quilombolas/locais frente a projetos de desenvolvimento turístico/imobiliário no litoral sul.

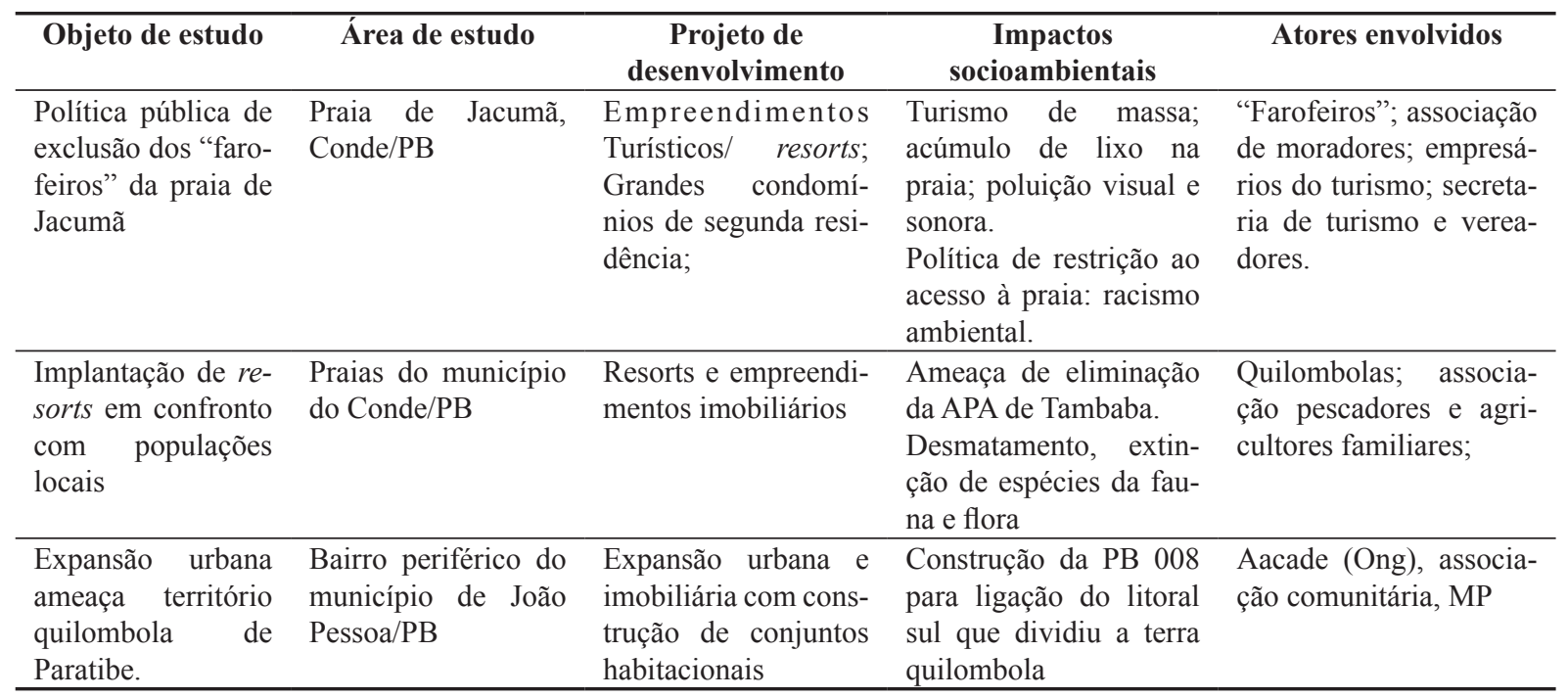

FONTE: Machado (2012; Espínola \& Andrade (2012); Peralta (2012).

busca inserção no mercado turístico, de outro foram excluídos indiretamente pela política municipal que restringiu o acesso dos "farofeiros" às praias da região. Para favorecer os empreendimentos turísticos, a retirada das barracas da praia, assim como a limitação do acesso dos frequentadores "incômodos", vistos como poluidores - não só pelo lixo deixado, como pela poluição sonora e pela "poluição visual" da paisagem - dando a esta política o caráter de racismo ambiental (Herculano \& Pacheco, 2006) 5 .

A comunidade quilombola de Paratibe, situada na periferia urbana do município de João Pessoa, formada por cerca de 100 famílias, foi também, segundo Relatório Técnico do INCRA (apud Peralta, 2012), afetadas pelo turismo no litoral sul, uma vez que teve seu território fracionado com a construção da rodovia litorânea $\mathrm{PB}$ 008, em 2002, para ligação do município de João Pessoa com as praias do litoral sul - o que favoreceu o aumento do fluxo turístico. Esta comunidade vem sofrendo, igualmente, pressões com a expansão urbana através da implantação de loteamentos e conjuntos habitacionais populares após sua transformação em bairro urbano. Com este cercamento, a comunidade se sente impedida de realizar os trajetos habituais devido aos muros dos novos loteamentos, além de lamentarem a perda de suas características rurais (Peralta, 2012).

A luta por reconhecimento e por direitos fundiários da comunidade de Paratibe tem recebido o apoio das ONGs Associação de Apoio aos Assentamentos de Comunidades Afro-Descendentes - Aacade e Coordenação Estadual Comunidades Quilombolas da Paraíba - Cecneq. No entanto, parte dos integrantes dessa comunidade rejeita a memória de remanescente de quilombo, de modo que o movimento local não vem conseguindo uma posição de unidade e consenso em relação a esta luta. Esta recusa ao autoreconhecimento seria manipulada por agentes externos interessados na expansão imobiliária da área, que apontam os riscos da titulação como território quilombola, pelo caráter coletivo da posse, impedindo posterior fracionamento para vendas por proprietários

\footnotetext{
5 Nos apropriamos aqui do conceito formulado por Herculano \& Pacheco (2006, p. 25) que definem racismo ambiental como "as injustiças sociais que recaem de forma desproporcional sobre etnias vulnerabilizadas", as populações de baixa renda e os grupos sociais discriminados.
} 
particulares que detém, atualmente, títulos de posse regulares (Peralta, 2012). Tal resistência com relação à autoafirmação do território quilombola também se apresenta entre as famílias dos assentamentos Gurugi I, Gurugi II e Ipiranga, que temem a anulação dos títulos individuais da posse da terra (Monteiro \& Garcia, 2010).

Contudo, jovens das comunidades locais, quilombolas, assentados rurais e pescadores artesanais do município do Conde vêm sendo alvo de uma política municipal de inclusão no mercado de trabalho turístico. Tal política envolve a parceria da prefeitura com uma escola estadual em João Pessoa, que oferece cursos técnicos profissionalizantes em nível médio na área de Hotelaria, Informática, Eventos e Serviço de Restaurante e Bar. A política está voltada não apenas para atender o mercado turístico existente, como também para estimular o desenvolvimento do turismo comunitário na área, de modo a favorecer o emprego decente no setor (Machado \& Andrade, 2013).

Outras experiências incorporadas à análise, neste artigo, envolvem o acesso a políticas públicas voltadas para o desenvolvimento local sustentável, por parte de grupos étnicos e de populações tradicionais/locais, definindo a outra lógica da ação governamental.

\section{Territórios étnicos/populações tradicionais, políticas sociais e desenvolvimento local}

Algumas comunidades tradicionais/locais da Paraíba têm vivido transformações significativas, resultantes do acesso às políticas públicas, as quais visam promover o desenvolvimento local sustentável como modelo alternativo ao desenvolvimento capitalista. Com o território reconhecido e demarcado pelas agências do Estado, as populações beneficiárias passam a receber uma série de ações governamentais, algumas vezes com intermediação de ONGs, gerando transformações visíveis no território, em graus diferenciados, em função da assimilação de novas práticas econômicas, as quais dão acesso a mercados e a créditos. É o caso da agricultura familiar e apicultura dos assentamentos rurais e dos quilombolas, da carcinicultura familiar indígena potiguara.

A pesquisa realizada no brejo paraibano investigou uma comunidade quilombola que viveu uma experiência de conflito fundiário envolvendo o autorreconhecimento como remanescentes de quilombo, por parte de um grupo de famílias quilombolas, moradores de uma propriedade de herdeiros dedicada à monocultura canavieira, vivendo em regime de semiescravidão (Peralta \& Andrade, 2012). Trata-se da comunidade Senhor do Bonfim, cujo reconhecimento pela Fundação Cultural Palmares ocorreu em 2005, sendo a primeira terra quilombola na Paraíba a ser beneficiada pelo Decreto Presidencial de Desapropriação por Interesse Social em 2009, embora ainda falte a última etapa de homologação.

Para mostrar um panorama das experiências dessas comunidades de perfil rural, na Paraíba, em processos de gestão comunitária compartilhada com setores públicos e terceiro setor através de políticas públicas direcionadas à melhoria das condições de vida dessas populações, ver a Tabela 3 .

A comunidade Senhor do Bonfim, composta por 22 famílias, cujo território de 120 ha foi conquistado através de luta, com o apoio da Aacade e da Cecneq. A pesquisa realizou uma análise da paisagem para detectar as transformações vividas pela comunidade com o fim do isolamento e da invisibilidade, após sete anos do autorreconhecimento como comunidade quilombola. Com o acesso a diferentes programas sociais, desde o Bolsa Família, a eletrificação rural, as cisternas de placa, entre outros, a comunidade iniciou um processo de gestão comunitária, revelando capacidade criativa e de ação com autonomia (Peralta \& Andrade, 2012).

Em contraste com os efeitos do autoreconhecimento em Bonfim, a comunidade de Paratibe foi alvo de uma análise comparativa no mesmo período em que revelou uma situação de fragilidade e de exclusão. Assim, o acesso a algumas políticas de desenvolvimento como o projeto Cinturão Verde, através da criação de galinhas, envolveu apenas 11 famílias, além da construção de 80 casas de alvenaria pela Prefeitura de João Pessoa, não produziu mudanças significativas para a comunidade. Devido ao alto custo da ração e ao tamanho das casas de $40 \mathrm{~m}^{2}$ - favorecendo os famosos "puxadinhos" - as ações limitadas não lograram efeito para desencadear um processo de gestão comunitária (Peralta, 2012). Entretanto, do ponto de vista da mobilização política, essa comunidade se encontra muito ativa em suas reivindicações, enquanto a comunidade do Bonfim, ao conquistar 
TABELA 3 - Experiências de gestão comunitária em comunidades étnicas e assentamento rural resultantes de programas sociais de desenvolvimento local na Paraíba

\begin{tabular}{|c|c|c|c|c|}
\hline Objeto da pesquisa & Área de estudo & $\begin{array}{c}\text { Programas de } \\
\text { desenvolvimento } \\
\text { local } \\
\end{array}$ & $\begin{array}{c}\text { Impactos ambientais/ } \\
\text { mudanças na } \\
\text { paisagem }\end{array}$ & $\begin{array}{c}\text { Atores sociais } \\
\text { envolvidos }\end{array}$ \\
\hline $\begin{array}{l}\text { Comunidade quilom- } \\
\text { bola Senhor do Bon- } \\
\text { fim, titulação e acesso } \\
\text { a políticas sociais }\end{array}$ & $\begin{array}{l}\text { Brejo paraibano } \\
\text { (município de Areia) }\end{array}$ & $\begin{array}{l}\text { Luz para todos; } \\
\text { Bolsa Família; P1MC } \\
\text { (cisterna), PRONAF; } \\
\text { PAA; Habitação }\end{array}$ & $\begin{array}{l}\text { Substituição da cana de } \\
\text { açúcar por agricultura } \\
\text { familiar, recuperação } \\
\text { de nascentes }\end{array}$ & $\begin{array}{l}\text { Associação Quilom- } \\
\text { bola, Aacade; Cec- } \\
\text { neq; Incra; MP; Go- } \\
\text { verno Estadual, }\end{array}$ \\
\hline $\begin{array}{l}\text { Carcinicultura familiar } \\
\text { indígena na terra poti- } \\
\text { guara e a busca da sus- } \\
\text { tentabilidade }\end{array}$ & $\begin{array}{l}\text { Tramataia no litoral } \\
\text { norte paraibano }\end{array}$ & $\begin{array}{l}\text { PPPI e PPRP - } \\
\text { Eletrificação rural e } \\
\text { viveiros de camarão - } \\
\text { COOPERAR-PB }\end{array}$ & $\begin{array}{l}\text { Desmatamento do } \\
\text { manguezal, poluição } \\
\text { no estuário por despejo } \\
\text { de efluentes }\end{array}$ & $\begin{array}{l}\text { Cooperativa de carci- } \\
\text { nicultores de Trama- } \\
\text { taia; Funai; IBAMA }\end{array}$ \\
\hline $\begin{array}{l}\text { Apicultura familiar em } \\
\text { assentamento rural }\end{array}$ & $\begin{array}{l}\text { Assentamento Tam- } \\
\text { baba no litoral sul }\end{array}$ & $\begin{array}{l}\text { Fundos rotativos so- } \\
\text { lidários BNB; PAA; } \\
\text { PNAE }\end{array}$ & $\begin{array}{l}\text { Conservação de matas, } \\
\text { plantio de arvores; }\end{array}$ & $\begin{array}{ll}\text { COOAP; } & \text { COOPER- } \\
\text { VIDA; } & \text { SENAES/ } \\
\text { BNB } & \end{array}$ \\
\hline
\end{tabular}

FONTE: Peralta \& Andrade (2012); Silva (2012); Sampaio (2013).

benfeitorias sociais, recuou na luta pela homologação definitiva de sua terra (Peralta, 2012).

A carcinicultura familiar Potiguara contou com um apoio técnico e financeiro inicial, mas os produtores indígenas passaram a vivenciar problemas ligados ao cultivo, de modo que vários deles foram obrigados a abandonar a atividade e arrendaram seus viveiros. Uma nova pesquisa deverá acompanhar este processo para avaliar as condições da atual gestão comunitária (Sampaio, 2013). É preciso enfatizar que as políticas públicas visando à elevação da renda ou à melhoria das moradias de grupos étnicos, não reconhecem o direito à autonomia desses grupos em suas formas de apropriação da natureza. A introdução de tecnologias como a carcinicultura, que degradam o ambiente ou a construção de casas em padrões massificados, em desacordo com os valores locais tradicionais, revelam a inadequação destas políticas.

A atividade da apicultura, ao contrário da aquicultura, que provoca grandes desmatamentos de áreas de manguezal, se caracteriza como atividade completamente ajustada à lógica da sustentabilidade, por requerer a conservação das matas. Essa atividade foi introduzida nos assentamentos rurais do INCRA do litoral sul - Assentamento Tambaba e Nova Vida -, sendo uma atividade gerida comunitariamente através de duas cooperativas vinculadas à apicultura, a Cooperativa de Apicultores do Estado da Paraíba - COOAP, e a Cooperativa de Agricultores Rurais de Nova Vida - COOPERVIDA. A produção do mel recebe recursos dos Fundos Rotativos Solidários oriundos da Secretaria Nacional da Economia Solidária - SENAES, repassados através de programas do Banco do Nordeste do Brasil - BNB. Para a comercialização, dita produção se beneficia de programas sociais como o Programa de Aquisição de Alimentos - PAA, e do Programa Nacional de Abastecimento da Merenda Escolar - PNAE (Silva, 2012). Percebeu-se que a existência de duas cooperativas atuando na gestão da apicultura poderia ser vista como um sinal de fragilidade dessa estrutura associativa (Silva, 2012).

Outras experiências incluídas neste painel de gestão comunitária, fora do universo rural, se referem a ações de gestão do lixo inseridas em periferias de espaços urbanos, em dois municípios, sendo um litorâneo integrante da região metropolitana de João Pessoa e o outro na região do cariri paraibano.

A gestão integrada do lixo constitui um campo de observação extremamente rico, porque permite observar a interação dos diversos setores da sociedade interessados no reaproveitamento ou na reciclagem, entre os quais a comunidade, o setor público, o privado e o terceiro setor. O reconhecimento do papel dos catadores na redução do volume do lixo urbano que seria destinado aos aterros sanitários e o seu reaproveitamento pelas indús- 
trias têm gerado benefícios sistêmicos para a sociedade, levando em última instância a políticas de inclusão deste segmento social, antes visto como lumpen-proletariado.

A primeira experiência consistiu na atividade de catadores de recicláveis de uma comunidade pobre da periferia da cidade de Cabedelo/PB vizinha à cidade de João Pessoa/PB. A segunda experiência resultou da implantação de um plano de Gestão de Resíduos Sólidos, a partir de ações do Ministério Público da Paraíba - MPPB, em uma cidade de pequeno porte do Cariri paraibano, conforme apresentado na Tabela 4.

Nas duas experiências investigadas, foi possível acompanhar duas modalidades de gestão: a primeira definindo-se como um modelo de cogestão entre a organização não governamental, Centro de Autoconhecimento e Meio Ambiente - Centro AMA e a Associação de Catadores de Recicláveis - ACARE, que buscaram parcerias com o setor público através da administração municipal de Cabedelo pressionada pela aprovação da lei dos resíduos sólidos (Gomes \& Andrade, 2012); a segunda representa um modelo integrado de gestão municipal, envolvendo vários agentes públicos (professores e alunos de escolas públicas, agentes de saúde, agentes do setor de comunicação), segmentos da sociedade (moradores e catadores) e setor privado (agentes do serviço de coleta do lixo urbano), com base em um plano de ação do Ministério Público da Paraíba, no município de Pocinhos no semiárido paraibano em 2012 (Souza, 2013).
A experiência da ACARE em articulação com o Centro AMA em Cabedelo representa uma forma de gestão com fraca articulação com o setor público. Na época da pesquisa, entre 2008 e 2009 (Gomes \& Andrade, 2012), a ACARE era composta por 31 catadores que percorriam um raio de $9 \mathrm{~km}$, cobrindo três bairros de classe média alta de Cabedelo - Poço, Camboinha e Intermares - para realizar a coleta dos recicláveis porta a porta, após um acordo com moradores dos bairros para fazer separação do lixo, recolhendo cerca de 10 t/ mês. Quanto à experiência de implantação de um plano municipal de gestão integrada por iniciativa do MPPB no município de Pocinhos/PB, foi possível acompanhar o processo de mobilização de diferentes segmentos sociais, dos agentes públicos aos moradores e catadores que ocorreu em um período curto de tempo, conseguindo mudar o comportamento da população (Souza, 2013).

Como resultado, foi observado que a gestão pública tornou-se mais eficiente com a desativação do lixão da cidade e com a instalação de um sistema de coleta seletiva. Neste processo foi detectado o papel da participação dos diferentes setores da sociedade para o êxito da experiência (Souza, 2013). Contudo, como as ações ligadas à gestão municipal do lixo está submetida a interesses políticos pouco claros, estes processos sofrem, com frequência, solução de continuidade, ocorrendo paralizações e retrocessos nos dois municípios pesquisados.

TABELA 4 - Experiências de cogestão do lixo em municípios da Paraíba entre associações comunitárias, ONGs e agencias municipais

\begin{tabular}{|c|c|c|c|c|}
\hline $\begin{array}{c}\text { Objeto da } \\
\text { pesquisa }\end{array}$ & Área de Estudo & $\begin{array}{c}\text { Experiências de } \\
\text { cogestão sociedade/ } \\
\text { setor público/ONG }\end{array}$ & $\begin{array}{l}\text { Impactos ambientais/ } \\
\text { mudanças na paisagem }\end{array}$ & $\begin{array}{c}\text { Atores sociais } \\
\text { envolvidos }\end{array}$ \\
\hline $\begin{array}{l}\text { Gestão comunitá- } \\
\text { ria/ Municipal de } \\
\text { resíduos sólidos ur- } \\
\text { banos }\end{array}$ & $\begin{array}{llr}\text { Moradores } & & \text { do } \\
\text { município } & & \text { de } \\
\text { Pocinhos no } & \text { cariri } \\
\text { paraibano } & & \end{array}$ & $\begin{array}{l}\text { Plano de gestão resíduos } \\
\text { sólidos municipal do } \\
\text { MPPB com apoio } \\
\text { de vários agentes da } \\
\text { comunidade local }\end{array}$ & $\begin{array}{l}\text { Presença lixão; serviços } \\
\text { precários } \\
\text { coleta urbana } \\
\text { lixo }\end{array}$ & $\begin{array}{l}\text { Secretarias educa- } \\
\text { ção, saúde e comu- } \\
\text { nicação; Professo- } \\
\text { res; agentes de saú- } \\
\text { de e catadores. }\end{array}$ \\
\hline
\end{tabular}

FONTE: Gomes \& Andrade (2012); Souza (2013). 


\section{O papel da participação nos processos de cogestão ou de gestão comunitária}

Para finalizar este painel, será feita uma análise sobre o papel da participação nos processos de gestão comunitária ou de gestão compartilhada com base nos dados recolhidos das pesquisas. A análise será assistemática já que não foi baseada em uma metodologia de avaliação de participação social, de modo que a apreciação feita é ainda muito preliminar.

As populações indígenas, quilombolas e os povos tradicionais, ao terem seus territórios demarcados e reconhecidos, tornam-se alvo de políticas públicas de inclusão dentro de uma proposta de desenvolvimento local sustentável, momento em que começam a ser procurados por agentes públicos e do terceiro setor com a oferta dos programas a eles direcionados. $\mathrm{O}$ acesso aos programas requer a criação de uma associação de caráter jurídico como exigência das instituições de fomento, seguindo princípios e normas que são estranhas às comunidades. Observou-se que as comunidades se adequam às exigências, mas, na maioria dos casos, as diretorias das associações coincidem com as lideranças tradicionais locais, de modo que acabam não sendo representativas de fato, rompendo com formas de solidariedade espontâneas. Conforme a análise feita por Peralta (2012, p. 42):

No caso quilombola, a obrigatoriedade da criação de uma associação, figura jurídica em nome da qual o título da comunidade será emitido, é outro exemplo contundente de como a mão do Estado tem a capacidade de impor um modelo de organização comunitária. Embora a formação de associações tenha sido um artifício inicialmente propício para resolver a questão de como garantir a coletividade da propriedade, muitas vezes produz alterações nas relações e contratos sociais preexistentes.

Apesar desta intervenção externa, imposta às comunidades substituindo lideranças tradicionais dos mais velhos por outras mais jovens, foi possível avaliar um avanço visível no aprendizado e no exercício da autonomia, especialmente na comunidade do Bonfim. Com a introdução de novas atividades de agricultura familiar, o processo de gestão revelou que os próprios membros da comunidade aprenderam a elaborar os projetos para participar dos programas de PAA e PNAE, apesar de manterem a dependência de ajuda externa para elaboração da prestação de conta. Entretanto, em boa parte das experiências, observa-se que a comunidade ao acessar os programas sociais desenvolve uma dependência em relação à assistência técnica fornecida, comprometendo a autonomia para continuidade da gestão comunitária.

Contudo, estes programas se fundamentam no princípio da participação social, de modo que, após a sua consolidação, espera-se que as comunidades envolvidas nos programas se tornem aptas a gerir, com autonomia, a atividade fomentada nos seus territórios. No entanto, o tempo imposto pelos programas parece insuficiente.

Torna-se imperativo, então, modificar o enquadramento formal dos projetos de desenvolvimento, estabelecendo cronogramas flexíveis e objetivos ajustáveis e em sintonia com as necessidades e possibilidades em nível local e regional (Drijver apud Foladori \& Taks, 2004).

No contexto da carcinicultura familiar indígena, a ausência de uma assessoria técnica explicaria os atuais problemas de ineficiência e de impactos ambientais. A introdução de atividade, que não fazia parte do universo das práticas e dos conhecimentos tradicionais dessa comunidade, deveria ter como requisito um acompanhamento com a inserção de inovações no sistema para torná-lo ambientalmente mais sustentável.

Já a apicultura no assentamento rural do litoral sul realiza uma gestão comunitária através de duas cooperativas, seguindo uma lógica da dádiva associada ao programa dos fundos rotativos solidários. Dessa forma, esse modelo de gestão foi caraterizado por Silva (2012, p. 96)

Eles trabalham em forma de mutirão para extrair o mel, e também na comercialização, quando um não disponibiliza o produto, o outro apicultor doa, para quando o primeiro disponibilizar devolver o produto que lhe foi dado, numa ética de reciprocidade e redistribuição, numa modalidade de Dádiva. 
Na experiência de cogestão dos materiais recicláveis, entre uma associação de catadores e uma $\mathrm{ONG}$, detectou-se uma dependência da assistência em relação à contabilidade do material reciclável feita por membros da ONG no galpão cedido pela prefeitura municipal de Cabedelo, como unidade de separação e de pesagem para venda dos materiais aos atravessadores que participam da cadeia produtiva dos recicláveis. Nesse processo de gestão, em que os catadores realizam o serviço de rua e a ONG a administração da contabilidade - quando não havia dinheiro para o pagamento direto do material coletado -, os catadores se sentiam livres para negociar seu material com outros galpões, deixando de fortalecer o projeto comunitário de que eram participantes.

Logo após a pesquisa houve interrupções na gestão comunitária relativa às duas experiências de gestão do lixo, devido a intervenções da política local em períodos eleitorais, demonstrando a fragilidade destas experiências. Quanto à participação do segmento dos catadores nas audiências públicas para tratar da gestão do lixo, tem se observado que eles não têm sido convidados, porém o comparecimento deles às audiências para protestar demonstra o grau de mobilização da categoria.

Diante desse conjunto de experiências, observa-se que a gestão comunitária requer, acima de tudo, diálogos entre os membros da comunidade, para se fortalecerem como grupo, e técnicos especialistas, para um aprendizado e uma troca de saberes a respeito das novas atividades introduzidas.

\section{Considerações finais}

A adoção, por parte do Estado brasileiro, de lógicas distintas de desenvolvimento tem levado a paradoxos, tais como o investimento em grandes projetos de infraestrutura energética, rompendo com a manutenção dos direitos territoriais dos indígenas, como também com a manutenção das Unidades de Conservação - UCs, ambas vistas como obstáculos ao crescimento capitalista. Ao mesmo tempo, o Estado brasileiro investe em políticas públicas direcionadas para os setores que sofrem exclusão do capitalismo globalizado, gerando processos de autogestão ou de gestão compartilhada que merecem atenção para que sejam avaliados sob a ótica da sustentabilidade socioambiental.

$\mathrm{Na}$ dinâmica dos conflitos territoriais envolvendo comunidades e grandes empreendimentos capitalistas, vale destacar que a disputa pelo acesso a recursos naturais define a natureza socioambiental dos conflitos identificados neste cenário. As pressões econômicas, quanto à instalação de empreendimentos públicos e privados, tendem a angariar o apoio do estado, negando ou atrasando as regularizações de terra de populações étnicas e tradicionais/locais.

Quanto ao acesso às políticas públicas, algumas comunidades pesquisadas não superaram, ainda, os riscos assistencialistas de algumas dessas políticas, tornando-se passivas diante dos programas sociais ou dependentes inteiramente da assistência técnica. Outras comunidades revelaram que já se encontram em processo de aprendizado de uma gestão compartilhada, devendo desenvolver a capacidade de resolver de forma autônoma e criativa os problemas que surjam em suas atividades produtivas, ao mesmo tempo em que procurem atender aos critérios de sustentabilidade.

Foladori \& Taks (2004) defendem que somente com a pesquisa dos antropólogos sobre as práticas relativas à vida material nas comunidades, contrariando a tendência dominante na antropologia de valorização dos estudos simbólicos da cultura, será possível perceber a diversidade de situações, como as ambivalências nas atitudes e nas formas de apropriação da natureza. Esta diversidade de formas de apropriação leva a graus distintos de degradação dos territórios ocupados pelos grupos étnicos e pelas populações locais, alvo das políticas de desenvolvimento.

Esse tipo de gestão deveria permitir canalizar as distintas percepções e discursos dos diferentes grupos envolvidos. Dessa maneira, será possível prevenir-se contra mudanças inesperadas e fortalecer a capacidade de resposta diante delas, em lugar de apenas remediar problemas ambientais. (Drijver apud Foladori \& Taks, 2004).

A introdução de inovações nas atividades produtivas na TI Potiguara, em território quilombola ou nos assentamentos rurais como a carcinicultura, agroecologia, apicultura, etc. podem ser compreendidas con- 
forme Sahlins (1997) no quadro da "indigenização da modernidade". De fato, povos indígenas vêm resistindo à aniquilação "tentando incorporar o sistema mundial a uma ordem ainda mais abrangente: seu próprio sistema de mundo (Sahlins, 1997, p. 52)."

Desta maneira, diálogos no âmbito de pesquisas envolvendo antropólogos e biólogos, visando a detectar práticas degradadoras ou sustentáveis em relação à natureza, poderão subsidiar a formulação ou a adequação de políticas de gestão territorial, com base no princípio da autonomia das populações étnicas e locais em seus territórios, bem como nos princípios da sustentabilidade ambiental.

Fóruns de discussão como os propiciados pelas pesquisas da Rede PRODEMA sobre a interface entre desenvolvimento e meio ambiente, nos tem auxiliado a pensar a natureza, não mais como dimensão exterior, mas conforme Latour (2004, p. 215) "naturalizada, quer

\section{Referências}

Arruti, J. M. Mocambo: antropologia e história do processo de formação quilombola. Bauru: Editora EDUSC - ANPOCS, 2006.

Barth, F. Grupos étnicos e suas fronteiras. In: Poutignat, P.; Streiff-Fenart, J. Teorias da Etnicidade. $2^{\mathrm{a}}$ ed. São Paulo: Ed. Unesp, 2011.

Cardoso, T. M.; Guimarães, G. C. (Orgs.). Etnomapeamento dos Potiguara da Paraíba. Brasília: FUNAI/CGMT/ CGETNO/CGGAM, 2012.

Castro, E. V. A inconstância da alma selvagem. São Paulo: Cosac \& Naify. 2002.

Cavalcanti, A. B. Caracterização e contribuições para a ostreicultura familiar no estuário do rio Mamanguape, Paraíba, Brasil. 2013. João Pessoa, Dissertação (Mestrado em Desenvolvimento e Meio Ambiente) - UFPB, 2013.

Cooperar-Paraíba. Plano de Participação das Populações Indigenas. João Pessoa, setembro 2007. Disponível em: <http:// util.socioambiental.org/inst/esp/consulta_previa/sites/util. socioambiental.org.inst.esp.consulta_previa/files/CP_Paraiba. pdf > Acesso em: 04 de Set. de 2013.

Costa, I. M. Tutela do Estado e autonomia indígena: a territorialidade e os direitos na visão indígena. CAOS Revista Eletrônica de Ciências Sociais, 21, 149-164, 2012. dizer, socializada, no próprio interior do coletivo em via de expansão.” Trata-se de incorporar a natureza na vida pública, de modo que os sistemas produtivos reconheçam as exigências da natureza com base na lógica da sustentabilidade.

\section{Agradecimentos}

Aos integrantes do GIPCSA e participantes da pesquisa, que contribuíram com o fornecimento e discussão dos dados e com o debate teórico de autores que fundamentaram este artigo. Aos Programa Regional de Pós-Graduação em Desenvolvimento e Meio Ambiente (PRODEMA) e Programa de Pós-Graduação em Antropologia (PPGA) da UFPB pelo apoio logístico e de infraestrutura. A CAPES pelo apoio financeiro a realização das pesquisas das co-autoras deste trabalho.

Costa, I. M. Terra indígena x terra de usina: legislação socioambiental e fundiária e os conflitos na TI Potiguara Monte Mor-PB. 05 fev. 2014. João Pessoa, Dissertação (Mestrado em Desenvolvimento e Meio Ambiente) - UFPB, 2014.-

Cunha, M. C. da; Almeida, M. W. B. Populações tradicionais e conservação ambiental. In: Capobianco, J. P. R (Org.). Biodiversidade na Amazônia Brasileira. São Paulo: Estação Liberdade/ Instituto Socioambiental, 2001.

Espínola, R. S.; Andrade, M. O. A inserção de resorts na costa de Conde/PB: impactos socioambientais na percepção do setor público, privado e comunidades locais. In: Lima, E. R. V. (Org.). Dilemas do uso e ocupação da costa paraibana. Vol. II. João Pessoa: Editora Universitária/UFPB. 115-134, 2012 (Série Pesquisa-Prodema).

Foladori, G.; Taks, J. Um olhar antropológico sobre a questão ambiental. Mana, 10(2), 323-348, 2004.

Gomes, A. E. S.; Andrade, M. O. A gestão dos resíduos sólidos urbanos na Paraíba: Parcerias entre setor público e terceiro setor. In: Aguiar, S. M. B.: Ribeiro, E. S. (Orgs.). Gestão Pública: práticas e desafios. Recife: Bagaço, p. 221-250, 2012.

Herculano, S.; Pacheco, T. (Orgs.). Racismo Ambiental. Rio de Janeiro: Projeto Brasil Sustentável e Democrático: FASE, 2006. 
Latour, B. Politicas da natureza: como fazer ciência na democracia, São Paulo: Edusc, 2004.

Little, P. E. Etnodesenvolvimento local: autonomia cultural na era do neoliberalismo global. Tellus, 3, 33-52, 2002.

Machado, A. A. Discurso ambiental, politica de turismo e exclusão social: uma análise sobre o excursionismo na praia de Jacumã, Paraíba. 2012. 128 p. João Pessoa, Dissertação (Mestrado em Desenvolvimento e Meio Ambiente) - UFPB, 2012.

Machado, A. A.; Andrade, M. O. A inserção de comunidades tradicionais no desenvolvimento do turismo: impasses e possibilidades. In: Anais da IV REA/XIII ABANNE. Fortaleza, jun. 2013. Disponível em: < http://www.reaabanne2013.com.br/ anais/edicao-atual/ > Acesso em: 20 de Jun. de 2014.

Medeiros, M. Etnodesenvolvimento e Desenvolvimento Local: contributos para um debate teórico. Ambiência, 7, 165-177, 2011 .

Mendes, A. B. Ambientalização de direitos e etnização das arenas ambientais: populações tradicionais e povos indígenas da Reserva de Desenvolvimento Sustentável de Mamirauá/ AM. In: Anais da $26^{a}$ Reunião Brasileira de Antropologia, Porto Seguro/BA, 2008.

Monteiro, K. S.; Garcia, M. F. Dos territórios da reforma agrária à territorialização quilombola: o caso da comunidade negra de Gurugi, Paraíba. Revista Pegada, 11(2), 2010.

Moreira, J. F.; Andrade, M. O. Índios carcinicultores e conflitos sócio-ambientais: sobreposição da TI com a APA da Barra do Rio Mamanguape/PB. In: Anais da 26 Reunião Brasileira de Antropologia, Porto Seguro/BA, 2008.

Moreira, J. F.; Andrade, M. O. O conflito de competências na gestão pública de uma APA: o caso da APA da Barra do Rio Mamanguape/PB, In: Aguiar, S. M. B. Gestão Pública: práticas e Desafios, vol III, p. 790-819, 2009.

Oliveira, J. P. Uma etnologia dos "índios misturados"? situação colonial, territorialização e fluxos territoriais. Mana, 4, 47-77, 1998.
Peralta, R. E. L. Desenvolvimento e Sustentabilidade: Novas interfaces para a luta quilombola. João Pessoa, Dissertação (Mestrado em Desenvolvimento e Meio Ambiente) - UFPB, 2012.

Peralta, R. E. L.; Andrade, M. O. Legislación y políticas públicas cambian el paisaje de comunidades negras quilombolas en Brasil. Revista REDPOL, 6, 2012.

Poutignat, P.; Streiff-Fenart, J. Teorias da Etnicidade. $2^{\mathrm{a}}$ ed. São Paulo: Ed. Unesp, 2011.

Sahlins, M. O "pessimismo sentimental" e a experiência etnográfica. Mana, 3(1), 41-73, 1997.

Sampaio, J. A. A. A carcinicultura familiar na Aldeia Indigena Potiguara de Tramataia: em busca da sustentabilidade. Projeto de dissertação do Programa de Pós-Graduação em Desenvolvimento e Meio Ambiente da Universidade Federal da Paraíba, 2013.

Silva, M. G. O homem e a apicultura: a Teoria do Ator Rede, reciprocidade e a sustentabilidade socioambiental, CAOS Revista Eletrônica de Ciências Sociais, 21, 91-100, 2012.

Silva, A. B. Uso sustentável do resíduo da atividade marisqueira na composição de material de revestimento de interiores em ecodesign. João Pessoa, Dissertação (Mestrado em Desenvolvimento e Meio Ambiente) - UFPB, 2013.

Souza, F. T. A Sustentabilidade e o papel da participação na gestão integrada dos resíduos sólidos: experiências da gestão pública e comunitária na Paraíba. João Pessoa, Dissertação (Mestrado em Desenvolvimento e Meio Ambiente) - UFPB, 2013.

Tosta, W. Cerco Articulado. 2013 (entrevista a João Pacheco de Oliveira) Disponível em: <http:/www.estadao.com.br/noticias/ geral,cerco-articulado, 1040280>Acesso em: 04 de Set de 2013.

Zhouri, A.; Oliveira, R. Desenvolvimento, conflitos sociais e violência no Brasil rural: o caso das usinas hidrelétricas. Ambiente \& Sociedade, 10(2), 119-135, 2007. 